Conclusion There was much agreement between paediatricians and GPs, as to the perceived importance of some of the stated presentations and skills, to the undergraduate curriculum, but it was also found that some of their views differed. Primary Care physicians have different perspectives, which should also shape the education provided for medical students. Future curriculum research should look to include other relevant professions, aside from specialists.

\section{G191(P) SO YOU WANT TO BE A PAEDIATRICIAN?}

A Anpananthar, N Ware, C Kingdon, R Klaber. Trainee Committee, London Specialty School of Paediatrics, London, UK

\subsection{6/archdischild-2015-308599.185}

Background There are a number of different career pathways facing paediatric trainees including academia, time out of training and subspeciality training. The careers advice they receive is dependent on their trainers and the trainees accessing the available resources and networks. The Royal College of Paediatric and Child Health has careers fairs for recruitment into paediatrics and is currently actively developing its mentoring strategy for paediatricians. The aim of this study was to assess the need for a careers fair

Methods A pilot regional careers evening for level 1 paediatric trainees was held in May 2014. As our level 2 and 3 trainees have the opportunities for peer networking at the existing regional training, this pilot careers evening was only aimed at level 1 trainees. The evening included talks on career pathways and signposting with questions and answer sessions with experts. Anonymous feedback was collated at the end of the event and 5 months post-event.

Results Of the 21 trainees who attended, 27\% had not had careers advice to date. $100 \%$ found the evening useful and all left with an action plan to explore their career options. Positive free text feedback included 'asking questions in informal manner, with immediate answers'; 'demystifying the Grid/general level 3 process'; 'discussion of different options available'; 'encouraged thinking about career plans'.

Of the $47 \%$ response to the post-event survey, trainees had sought careers advice from their educational supervisors or tertiary units, had become involved in management activities and looked into out of programme options. All had attributed these actions to the careers evening and most found the evening ' $u s e$ ful' or 'inspiring'.

These results were discussed in focus groups, comprised of training programme directors, college tutors, trainee committee members and trust representatives, to shape the programme for the next paediatric careers event.

Conclusion The feedback was overwhelmingly positive with high demand for it to be held annually in our region. It will be open to all paediatric trainees, which will also further enable the senior trainees to provide careers advice in their future roles as educational supervisors and mentors.

\section{G192(P) 'THE DAY THE SIMULATOR DIED' - A PILOT}

1,2LC Budd, 1,2S Pawley. 'Children's Emergency Department, Royal Alexandra Children's Hospital, Brighton, UK; ${ }^{2}$ Department of Paediatrics, Brighton and Sussex University Hospitals NHS Trust, Brighton, UK

\subsection{6/archdischild-2015-308599.186}

Aims We wanted to evaluate the educational value of a new inter-professional simulation day - 'The Day the Simulator Died'. Methods This day comprised introductory lectures, 2 high fidelity simulations of unsuccessful resuscitations including a simulated parent and communication skills sessions addressing breaking bad news and unexpected child death procedures. Immediate feedback was sought and a follow up questionnaire was sent 4 months later.

Results The pilot day had 9 participants -8 answered the follow up questionnaire.

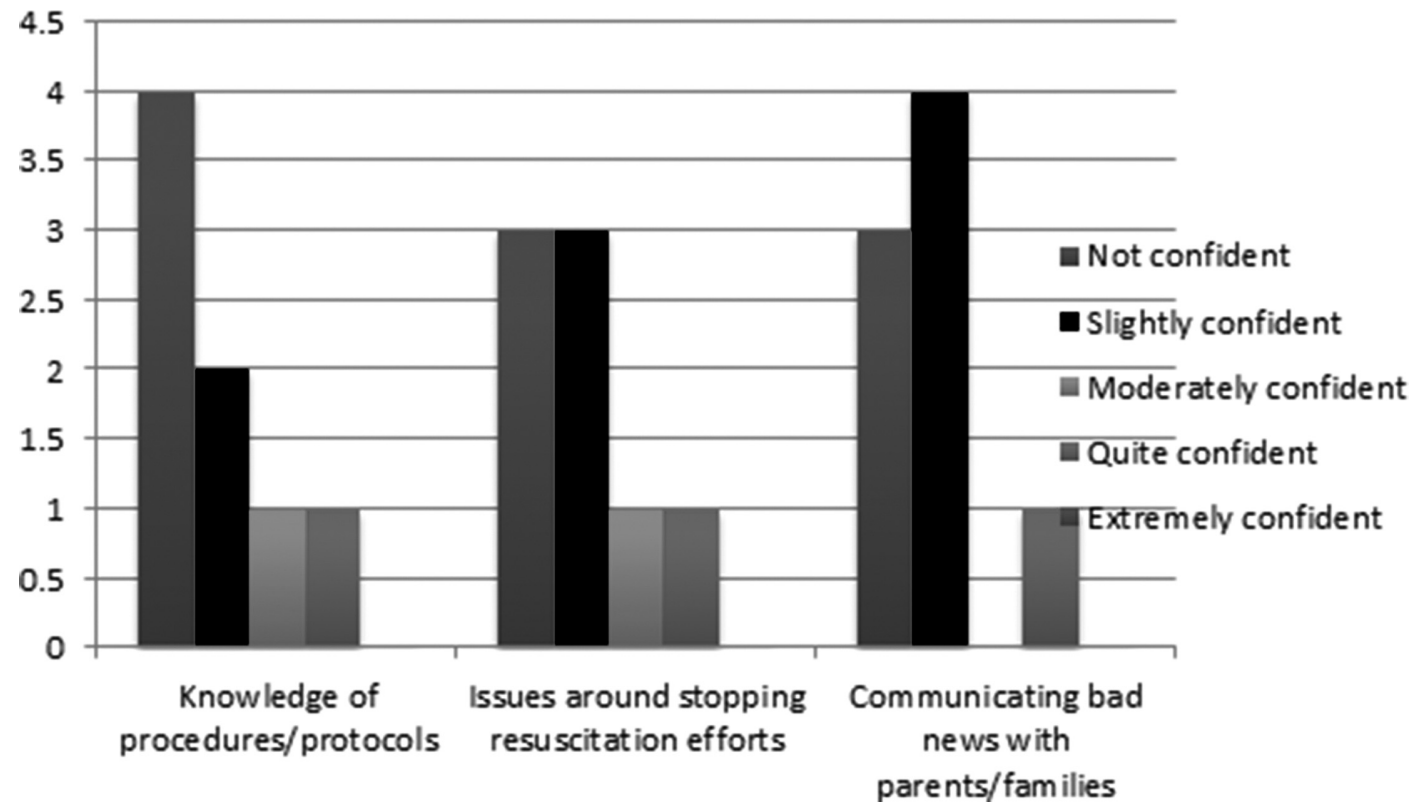

Abstract G192(P) Figure 1 Pre-simulation day confidence 


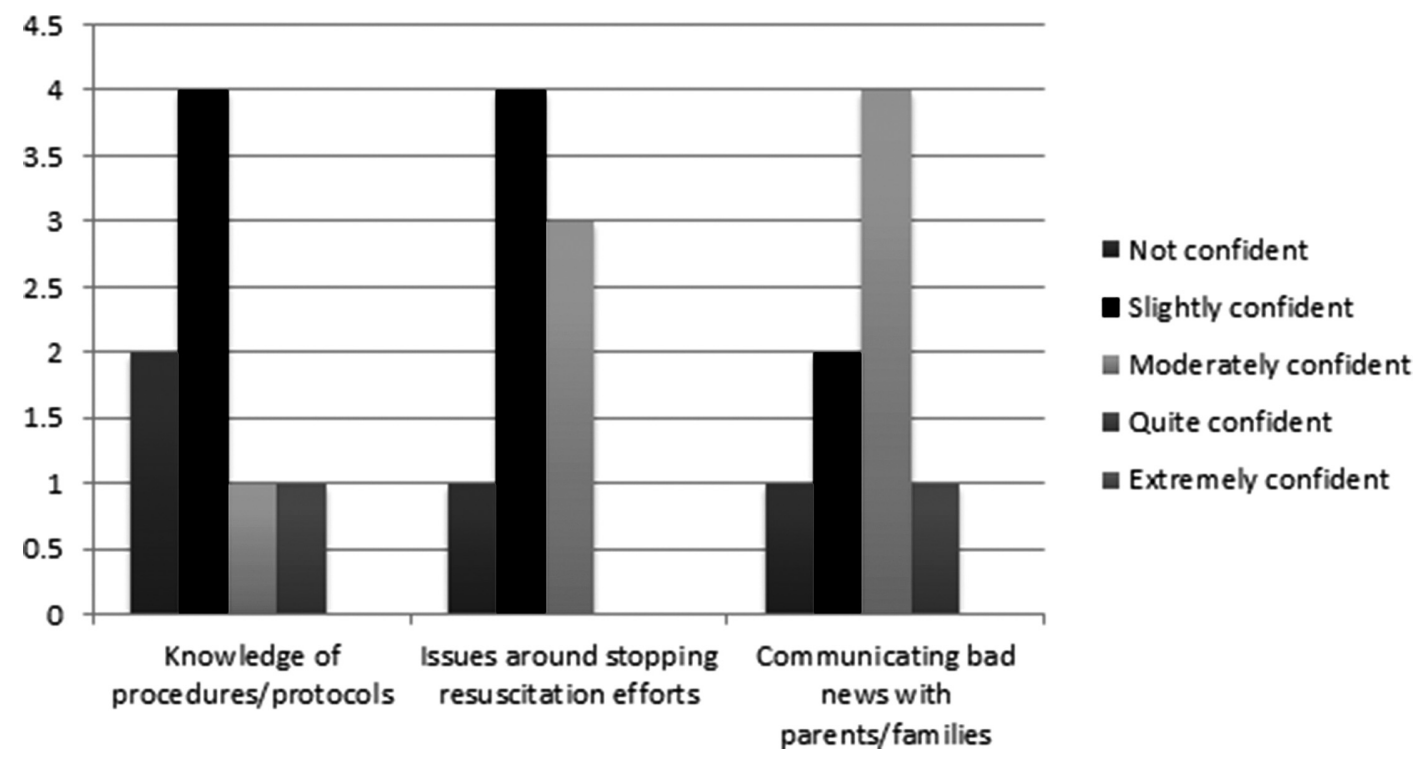

Abstract G192(P) Figure 2 Post-simulation day confidence

\begin{tabular}{lc}
\hline Demographics of participants & 1 \\
\hline Consultant Paediatricain & 2 \\
Level 3 Paediatric Trainee & 2 \\
Level 1 Paediatric Trainee & 1 \\
Broad-based Training Trainee & 3 \\
Paediatric Staff Nurse & \\
\hline
\end{tabular}

The group had varied prior experience. 50\% had no previous formal training on child death procedures or breaking bad news. A significant proportion (5 of 8 ) had either no experience or had only been the primary deliverer of bad news on fewer than 5 occassions. Limited exposure to informal training opportunities including observation of such encounters and feedback within the work place were also reported.

The graphs highlight the positive impact of this training with an increase in self-reported confidence (Figures 1 and 2).

Simulated parents were rated as being very useful and being immersed in high fidelity simulation prior to these difficult discussions was viewed as helpful; increasing the realism.

Conclusion We have highlighted an area of practice where selfreported confidence is low as a result of limited opportunities for training and feedback that stem from unexpected child death being an infrequent event. This pilot simulation day was well received and resulted in an increased confidence amongst participants. Plans are in place to further this training and to widen the multi disciplinary team involvement.

\section{British Academy of Childhood Disability and British Paediatric and Adolescent Bone Group}

\section{G193 MAGNETIC RESONANCE IMAGING (MRI) SCANS IN CHILDREN WITH NEURODEVELOPMENTAL DISABILITIES: SHOULD A PAEDIATRIC NEURORADIOLOGIST'S OPINION BE SOUGHT?}

M Govindshenoy, S Hennigan, R Ahmed. Paediatrics, Walsall Healthcare, Walsall, UK

10.1136/archdischild-2015-308599.187
Background At our local hospital MRI scans of children with developmental disabilities are reviewed by radiologists who provide the preliminary report. It is the choice of the treating paediatrician to seek further specialist paediatric neuroradiologist's opinion.

Aim Did differences in local and specialist opinion impact on diagnosis?

Method Concurrent MRI scan reports of children with neurodisabilities from the local radiologist and the neuroradiologist were compared.

Result 63 children had reports from local and specialist radiologist. All had neurodevelopmental difficulties from mild to severe range.

The results were divided into three categories:

Group 1: Where there was significant difference in opinion: 26 reports (41\%) Periventricular leucomalacia (PVL) was detected in 11 of which 10 had spastic cerebral palsy. Other cases included the following: antenatal hypoxic Ischaemic encephalopathy (3), thinning or agenesis of corpus callosum (4), disorder of myelination (3). The specialist was more likely to detect disturbances of myelination, (delay, loss or degeneration) The specialist also ruled out (6\%) white matter loss (3) and absent corpus callosum (1) reported by the local radiologist.

Group 2: Where there was no difference in opinion: 29 reports (47\%) The majority of these children (15) had global developmental delay without spasticity. Other cases included tonsilar herniation (2) Corpus callosum dysgenesis (2) hypoxic ischaemic encephalopathy (1) periventricular leucomalacia PVL (2), Cytomegalovirus infection (2) and hemisphere infarct (1) autism (2).

Group 3: Only subtle differences in report which did not impact on diagnosis: 8 reports (13\%) These included arachnoid cysts, aberrant patterns of myelination, age consistent delay in myelination and benign extra cerebral space enlargement.

Conclusion This study showed that a paediatric neuroradiologist's opinion is important and could impact on the diagnosis very significantly. They detected and ruled out abnormalities in $41 \%$ of cases resulting in conclusive diagnosis compatible with clinical findings. Periventricular leucomalacia (PVL) was more likely to be detected by the neuroradiologist and was the commonest finding contributing to clinical diagnosis. In children 